\title{
Violencia, política y escritura. Gabriela Cabezón Cámara*
}

* Fecha de recepción: septiembre de 2015. Fecha de aceptación: marzo de 2016.

\section{(4) Nancy Fernández***}

\section{Resumen}

Este texto procura abordar la escritura de Gabriela Cabezón Cámara, una de las narradoras de mayor impacto en la actualidad. En esta línea nos proponemos analizar el trabajo que realiza con la representación de problemas políticos y culturales y a su vez aquellas formas que hacen visible una mirada a partir de un modo singular de concebir género, sexo, lengua, literatura, periodismo y producción artística.

\footnotetext{
Abstract

This work attempt to address the Gabriela Cabezón Cámara's writing, one of the narrators with the greatest impact at the present. In this line, we propose to analyse her work with the representation of political and cultural problems and at the same time, those forms that make a view visible from a singular way of conceiving gender, sex, laguage, literatura, journalism and artistic production. This text seeks to address the writing of Gabriela Cabezón Cámara, one of the narrators with the greatest impact at present. In this line we propose to analyze the work he does with the representation of political and cultural problems and at the same time those forms that make a view visible from a singular way of conceiving gender, sex, language, literature, journalism and artistic production.
}

\section{Palabras clave:}

escritura, arte, género, política

\section{Kew words}

Writing, art, gender, politic 
"Fire walk with me".

Twin Peaks

$1 \mathrm{El}$ arte de la instalación, que según Boris Groys no solo es arte sino la forma emergente más plena en el contexto de la cultura contemporánea porque opera como el reverso de la produccir Desde esta perspectiva, la instalación extrae una copia del supuesto espacio abierto y aséptico de marcas respecto de la circulación anónima y la ubica, aunque sea provisoriamente, en el contexto fijo, estable y cerrado de un "aquí y ahora" topológicamente bien definido. La instalación supone así el desplazamiento de la "iluminación profana" para una recolocación del aura, interactuando con nuevas topografías y territorialidades (Groys, 2015).
Villeros, víctimas de trata de personas, ocupas. Estos son los mundos que Gabriela Cabezón Cámara ficcionaliza en La Virgen Cabeza, Beya y Romance de la Negra Rubia respectivamente, cuyas narradoras oscilan entre la primera, la segunda y la primera persona, en este mismo orden. Y aquí se configuran las instancias de enunciación donde los sujetos, en cada texto, construyen su discurso no solo al margen de la ley, sino también al del principio identitario de unidad. Los personajes cambian, por contingencia y por elección; o mejor, porque deciden, en la fugacidad de un instante, el signo definitivo de sus vidas. Si algo opera en las tramas es una movilidad, que algún modo de lectura podría asociar a un tipo de acción estructural. Sin embargo, creo que el exceso provoca el plus del mero avance argumental, colmo de las turbulencias donde las decisiones o los sucesos desmedidos que, sin ser buscados, golpean como maza. O quizás, un principio de atracción por el cual cada personaje se extiende y distiende en la dirección incierta para que, en algún lugar, la decisión se juegue por el destino final. Personajes y cosas varían, objetos de una suerte mudable. Así, la Virgen, el pedazo de cemento idolatrado por miles de fieles, se cubre hacia el final, y ya en Miami, de una coraza de zafiros y diamantes. También la Negra (en la tercera de las novelas) de ocupa deviene bonza, pedazo de carbón e instalación artística a portadora del bello rostro de su amada alemana, vía intervención quirúrgica. ${ }^{1} Y$ sin remilgos obsecuentes, la narradora no duda en su enojo con Cleopatra, en escribirle una carta llamándola por su nombre masculino y femenino; más aún, increpándola casi en calidad de "marido". Pero se hace necesario anotar que aunque el personaje protagónico se constituya en función de un mundo compuesto de hechos que registran problemáticas sociales, el costado individual es la otra cara del grupo o de la comunidad. Aquí es donde ingresa la torsión del límite entre el humor y el testimonio, o más aún, la representación cuyo simulacro realista alterna simultáneamente entre la celebración, la supervivencia, la venganza y la muerte. Si es cierto que los textos, en especial La Virgen Cabeza y Beya, inscriben asuntos contemporáneos, sociales y políticos, con la dosis necesaria de abstracción para que la generalidad se traduzca en concepto, el humor corta precisamente ahí donde el "realismo" podría exigir las convenciones de la denuncia y el testimonio. Porque las novelas se proponen mostrar, y descarnadamente, la violencia desenfrenada que impregna y asfixia el mundo de los marginados; pero en ese proceso de hacer visible lo que está oculto por las crónicas del periodismo, o bien oficial, o bien funcional al crimen organizado, la autora quita los goznes que regularían el justo equilibrio entre ironía e interpelación, entre literatura y periodismo.

Así como el descontrol forma el humus del suelo villero con semen, sangre y restos festivos del banquete de putas, rateros y chongos, es el ritmo cumbiero el que hace saltar de un registro a otro sin demasiado respeto por supuestas normas de representación. En ese límite cenagoso se produce, entonces, una escritura que procesa la política como hecho estético de una imagen policromática, de voces alzadas y revólveres empuñados. Voces clausuradas en el silencio que se manifiestan en televisión, estruendosas, en un lugar corrido del habitual asignado al arte, entre las misas ofrendadas a la Virgen y la resaca de las fiestas sexuales; así también, la bonza exhibida en la bienal de Venecia y hasta el trazo en blanco y negro de Beya, producto del diseño de Iñaki Echeverría, sacan a la calle y fuera de sus cauces, los gestos performativos en tránsito de volverse hecho artístico.

Este, quizá, resulta ser el punto donde las prácticas simbólicas se cruzan o mejor, se constituyen en el límite mismo del arte y la vida, volviendo a distribuir, genuinamente, los lugares de lo sensible. Bioarte que guarda para el trabajo con el lenguaje, el 
procedimiento y el resultado de un barroco en sintonía con el siglo XXI. ${ }^{2}$ Alambiques y florilegios que caben en la serie de Lamborghini y Perlongher.

Para que la performatividad del gesto artístico demuestre toda su potencia y su eficacia, la productividad tiene que volverse, en cierto modo, amnésica y a su vez, paradójicamente, capaz para descorrer los velos de la nostalgia y la melancolía. Golpear, insistir allí donde aún persiste una traba para que movimientos, opciones y afectividades formen la pregnancia que actos y participación inyectan en la condición colectiva. Esta es la concepción ética y estética que Cabezón Cámara tiene de la escritura. Y pensando en los tres textos, hay un motivo que produce esa fusión de estados, sensaciones y registros, enhebrando, disruptivamente pero en continuo, la producción textual: ese motivo singular es el fuego.

Sería viable pensar en algunas series, más bien cruces, no articulaciones estructurales. Entonces podríamos leer ciertas inscripciones que interfieren tanto las exigencias de precisión informativa como las figuraciones que tiendan hacia la afirmación de una realidad acotada en presupuestos referenciales, en el crédito concedido a la idea de verdad. Y es que la verdad se instala en los tres textos de Cabezón Cámara, más como imaginario y problema, más como construcción de las condiciones artísticas, materiales e históricas de una auténtica toma de conciencia, que como acta notarial de datos verídicos. Si en Beya. Le viste la cara a Dios, la autora se ocupa de la trata de personas tomando los testimonios de mujeres que sufrieron ataque, secuestro, tortura, explotación sexual, abuso y ultraje, desaparición y muerte, el nombre consignado en el título es la alusión deformada de los cuentos de hadas. Es el uso de la tradición por vía del oxímoron. Y es posible que esto mismo sea un modo que permita contar y dar cuenta (destapando y sacudiendo), la entrada y el recurso de una toma de distancia que implica el primer paso de la ficción, para poder decirlo todo. Por eso mismo, no voy a insistir en la conocida categoría dual: factio-fictio. 'Hecho', la dimensión de lo fáctico como lo dado de la verdad una e implacable; sin embargo, también, dimensión transdiscursiva desde el momento que 'hecho' en cuanto suceso supone además, desde su raíz etimológica, 'armado', 'construido'. La ficción, en cuanto textualidad, es resultado que negocia con los parámetros de un saber previo, en este caso, violencia de alto voltaje singularizada en determinado personaje que le otorgue eficacia: ética y estética. Y podríamos agregar: los datos están como base o materia prima, como motivos y soportes de lo que va a constituir, para Cabezón Cámara, el auténtico problema para escribir, para leer, para pensar.

Romance de la Negra Rubia. Pareciera que las figuraciones de la contemporaneidad son la marca de lo social. Y en el caso de Romance..., el punto de partida son los desalojos. Disparador que está lejos de promover una mirada etnográfica, mediante el recorrido de la observación fotográfica o fílmica, ya que todo eso ingresa en la trama para envolverse en el torbellino de un lenguaje alucinado por las orgías, el alcohol y las drogas. Sin embargo, y más allá de la ausencia de una función documental que queda anulada en el pasaje que va de ocupa a líder y millonaria, la narradora plantea el modo de narrar, el comienzo posible que solo le revela la imposibilidad de totalizar. Empezar a contar por cualquier lugar para decirnos, a modo de anticipo, que todo lo que sucedió es producto de los relatos, diversos, fragmentados, versiones: los vecinos, el coro. Ella sale de un coma farmacológico, luego de ser carne narcotizada de su propia hoguera, la que había destinado a los ratis que irrumpen en la vivienda tomada. Pero como todo, o casi todo, en las historias de Cabezón Cámara es remolino de puro azar, la bonza inconsciente deviene santa. Así crea su propia mitología y fija las pautas y reglas de su propia credibilidad. Líder casi muda, empleando apenas un conciso lenguaje de señas, reliquia carbonizada ante un grupo de testigos convencidos de un acto de sacrificio y de inmolación. Y si el problema empieza con el modo de narrar, sobre un blanco que intenta reconstruir, la protagonista pone énfasis explícito
2 De Foucault a Ludmer, de Schopenhauer y Nietzsche a Christian Ferrer, el prefijo 'bios' atañe a una intervención en la vida y de la vida sobre prácticas simbólicas que tienden a desnaturalizar el concept esencialista de 'vida', de lo humano, de la identidad y de la subjetividad fija, así como de los límites que, presuntamente, la separan de otros conceptos. No solo se trata aquí de pensar en las fronteras lábiles entre pensar en las fronteras lábiles entre Detos saberes, sino de pensar un lugar propicio para la técnica, la tecnología y los procedimientos formales que destraban nociones anquilosadas, aquí, en el arte y la estética. En este caso, propongo la perspectiva que Gabriela Cabezón Cámectiva que Gabriela Cabezón Cámara no solo desarrolla en su Este punto de vista se completa con la anterior nota a pie (Fernández, 2016). 
en la noción de comunidad cuando repite, al modo militante de una portadora de la memoria colectiva: "los míos". Podría decirse que algo o mucho de eso ya estaba en La Virgen Cabeza, pero acá se precipita en el sentido de resto, de deuda y de duelo. Es la falta, el déficit, lo que une marcando el menos. Porque nunca habla de suma gregaria, sino de la muerte y del silencio que el sistema, social y político, debita en la cuenta de los que siguen vivos. Comunidad es también la comuna de los corifeos, y los que repiten la métrica popular del grupo que inventan; artistas, poetas y militantes creyentes y sostenes de la invención fundante, a partir del primer estallido (Cabezón Cámara, 2009: 32). El devenir de los personajes es compatible con el tono tragicómico; en el mismo nivel, la risa interrumpe el drama y quien mejor lo va a confirmar es la impasibilidad con que la amada de la narradora enfrenta su propia enfermedad y muerte: de tal modo, el entierro será una fiesta hecha a su medida. Y como en La Virgen Cabeza, la convención normativa de algún verosímil realista (total, objetivo, general, histórico) queda disuelta en el pasaje veloz que va del infierno y la muerte a la gloria del amor y la fortuna. El dinero, los millones incontables, parecen funcionar como motivos, esquirlas de una materia prima narrable que se extiende hacia zonas imprevistas. Dinero para especular hasta dónde podría llegar el exceso del derroche; y quizá, como anverso de la miseria, activando el relato donde la pobreza cierra toda posibilidad de narrar.

En cuanto lenguajes, el rezo y la plegaria, la fe así como su reverso, el descrédito sarcástico y el trance hacia un estado de dolor y de furia, es lo que, en parte, cuentan los textos. Así también es el lenguaje, directo en su efecto, en el impacto de una literalidad tan certera como demoledora. Las palabras por su nombre. Si bien juega en los bordes de la alta cultura, la cultura popular y la masiva están presentes desde los formatos massmediáticos hasta las jergas y los argots de las lenguas más privadas: minorías, grupos, tribus, sectores. Asimismo, la escritura tampoco es ajena al modo digital ni por referencia ni en sus mismas condiciones de producción; las nuevas tecnologías forman parte del soporte, del surgimiento (en el caso de Beya) y de los motivos de una realidad parcial, porque los personajes, en cuanto imágenes de sujetos, son atravesados por los nuevos lenguajes cibernéticos. Respecto de Beya. Le viste la cara a Dios, si bien recoge los elementos testimoniales de los casos que se conocen más y los que no, el tratamiento de la corporalidad sobre la base del abuso sexual desplaza al personaje central del lugar de víctima para reconvertir la humillación en pura rabia. Así, Beya puede, a tono con el diseño gráfico de Iñaki Echeverría, asumir el rol de una heroína que a partir de una suerte de desdoblamiento místico pasará a hacer justicia por mano propia. Sujetada a una cama, tal como la misma autora lo ha hecho explícito, la nouvelle se desprende del cuento de hadas donde la protagonista duerme; con la salvedad de que aquí se devela, sin parodia, el horror de un itinerario que va de la vejación extrema a la ira desenfrenada, de la reducción a un estado infra a la explosión de un estado de guerra. De esta manera, la protagonista excede el sometimiento a una condición animal para abrir fuego sobre captores y enemigos. La visibilidad de la gráfica, las líneas, el cromatismo escueto en blanco y negro, por un lado pone distancia de la mera catarsis identificatoria. Por otro, la literalidad de las expresiones en los dibujos de Echeverría complementa el lenguaje directo, el movimiento que aporta el léxico en el grado máximo de su crudeza, impactando en el centro de la presentación; se trata de mostrar, más que representar, y en carne viva, el centro vulnerable de los cuerpos, el dolor. Tortura, violación, secuestro, desaparición. Por eso, la voz en segunda persona, resulta un modo de objetivación extrañada, un rictus suplementario para completar y dispersarse en el trance místico, no solo para hablar y contar sino para tomar una suerte de línea de fuga que la ayuda a preservar su alma en alguna morada salvadora. Un lugar, "en un reino muy lejano" del antro de clausura aberrante, cuyo salvajismo reenvía a la tradición de mataderos, reses y faenas carniceras. 


\section{La Virgen Cabeza}

Anteriormente, mencionaba la posibilidad de pensar en cruces y series. Para comenzar podríamos señalar, en primer término: la serie social. Acá se juega la elección de un territorio: la Villa, El Poso. Con resonancias conocidas por nosotros, la villa, frente al cordón protector del barrio residencial de los nuevos ricos. Allí comienza la trama oscura de las complicidades inherentes al negocio inmobiliario, y del secreto a voces de los intereses que encubren la compra de tierras para la construcción de lugares de esparcimiento, de countries, barrios privados para una vecindad selecta. Por eso, el territorio también es la ciudad -incluso el ámbito palermitano que la protagonista abandona- y el Conurbano - el infierno bonaerense que propicia la trata de personas y el narcotráfico-. Allí está el suburbio, jirones de cuerpos bajo tierra, orilla cuyos restos de ruralidad borran las huellas del crimen organizado entre delincuentes comunes y la jerarquía policial. La misma noche silenciosa en que Qüity queda paralizada de terror en medio de la pampa nocturna y siniestra es la que la lleva, sin que ella conscientemente lo sepa, hacia la zona concentrada, abigarrada, ruidosa y colorida. Sin el mínimo asomo de pintoresquismo, la villa satura sexo y violencia; pero también, prácticas de rescate entre los escombros, antes de y durante el operativo de erradicación. Así, Qüity deambula, sonámbula de drogas, desde el sacrificio a la piedad, esa misma noche en el medio de la nada cuando de pronto escucha ruidos de alerta y ve una ráfaga de fuego sin rumbo: en ese instante le da el tiro de gracia a la prostituta adolescente quemada viva. Esa noche es la que marca un viraje en la vida de Qüity, para no volver nunca al punto de partida. Ese será el punto de inflexión para que se transforme en otra. En este sentido, la narradora también cruza hacia el margen y la clandestinidad a partir de la zona fronteriza que transitaba en su trabajo de cronista policial. Entonces, hay relación entre territorio y género, sexo y figuración identitaria. La subjetividad de Qüity se emplaza en la autoafirmación consciente: "La maté y ella me hizo villera" (Cabezón Cámara, 2009: 49).

Podemos hablar de series y, arbitrariamente, numerarlas, procurando la ficción de un orden. Primera serie: el sexo, el género. ${ }^{3}$ Aquí se despliega toda la materialidad que tenga que ver con el mundo de los afectos, las sensibilidades, los cuerpos. Aquí rompe definitivamente con el mínimo asomo de un estereotipo. Desde el amor a la violencia, siempre entre los extremos. Y siempre funciona la elección, de la decisión y del deseo. Subjetividades cuya clave es la inscripción de lo aprendido, de lo forjado con deliberación. Madre, macho - huye vestida de hombre-y hembra de su esposa travesti, Cleopatra, que la penetra como nadie. De la heterosexualidad ilimitada (los pibes villeros, Jonás, el sobrino de Cleo y, que antes de ella, es la brújula fálica; Jonás, o el imán desesperante) a la atracción que deja bien afuera los relentes de culpas y pecados. La atracción lo "explica” todo, la razón necesaria sin causa suficiente pero que también es el reverso y la condición parcial de la afectividad. Parcial porque el deseo y el impulso también dan cuenta de un proceso, y esto es, la experiencia del aprendizaje, en el sentido de que el mundo de los afectos y de los lazos comunitarios se eligen, se construyen, se sostienen y se aprenden. Así, Qüity se desplaza de la heterosexualidad (los pibes, Jonás) a Cleo, la líder villera y predicadora, la autoridad litúrgica entre la calle, la cárcel y la prostitución. Entonces, la Virgen Cabeza es salvación y esa sentencia apodíctica trama el sistema de creencias que ella misma origina en el relato de su detención; después de ser golpeada y violada grupalmente en la celda de una seccional, Cleo tiene una visión mística, se levanta como si nada hubiera sucedido y perdona a sus agresores. Pero en calidad de travesti, Cleo ejerce la plenitud de sus atributos y es la mujer con pene. Y todas sus variaciones entre lo masculino y el simulacro de femineidad a lo Doris Day. No digo copia. Un travesti es simulacro porque vacía de esencialismos al supuesto modelo. Cleo pone de manifiesto la disolución de límites y rótulos entre la exclusividad binaria.
3 Cabezón Cámara, en sintonía con las teorizaciones de Judith Butler y las ficciones de Monique Wittig, hace funcionar mecanismos contra la idealización de aquellas expresiones de género que originan formas de jerarquía y exclusión. En este sentido, sus textos, sobre todo La Virgen Cabeza y Romance de la Negra Rubia, plantean la eficacia de las prácticas sexuales no normativas, cuestionado la estabilidad del género como categoría de análisis. De este modo, poniendo en crisis la ontología, naturalizada en la tradición atávica de un esencialismo, Cabezón Cámara permite reformular los niveles de la sexualidad y del lenguaje en el sentido de la transformación permanente de las identidades, en su condición provisional. No es otra cosa lo que los teóricos queer establecieron cuando distinguen entre género y sexualidad, rechazando que exista una relación causal o estructural entre ambos. Asimismo, resulta productiva la idea de performatividad de género, en la relación establecida entre un acontecimiento, podría decirse, y el efecto y la acción. Butler plantea esta línea en su lectura de la interpretación de Derrida sobre "Ante la ley", de Kafka, y donde la anticipación juega el rol de instalar autoridad y expectativa. Trasladando esto a la cuestión de género, lo que se emplaza es la idea de una esencia interior que produce el fenómeno mismo que anticipa. En esta línea, respecto del travestismo, al cual no considera como modelo de acción subversiva, Butler se pregunta por la realidad del género en tanto las percepciones que se introducen mediante el símil vacilan como experiencia de una figuración, borrando la frontera que pasa de lo real a lo irreal. Tanto Cabezón Cámara como Butler Tanto Cabezon Cámara como Butler la legitimidad para prácticas y cuerpos, en la medida en que las normas del género (dimorfismo ideal, complementariedad heterosexual, dominios de la masculinidad y la feminidad) determinan lo que será inteligiblemente humano y lo que no (Butler, 2009). 
Segunda serie: las afectividades elegidas. Y podríamos añadir, experiencia de las afinidades. Entre la tragedia del desastre provocado por los que ejercen el poder, y los episodios desopilantes de rituales comunitarios; entre las liturgias villeras y los delirios oníricos llevados a los recitales cumbieros de la emigración a Miami, se encuentra Daniel. El hombre que es servicio de inteligencia y que, además, lee el aura de las almas. Daniel es un personaje a la medida de Qüity, una suerte de parapolicial, un servicio converso y atraído hacia la necesidad de dar, en la plenitud de la palabra, toda la protección a Qüity, algo de hija, de amante, amiga y hermana. Daniel, segmentado entre la fría "racionalidad" de los operativos policiales y su inevitable voluntad de proteger a Qüity, el mayor de sus lazos afectivos. Ahí opera la redefinición y redistribución de lo sensible, un amor que excede rótulos y funciones y que solamente se sostiene, ni más ni menos, que por la entrega ilimitada y el cuidado que no espera retribución alguna. Son vínculos, dejando otra vez afuera el imperativo categórico y el mandato cultural y moralista que establece los límites que acatan normas, que imponen y respetan tabúes, los tipos y estereotipos de las relaciones interpersonales.

Tercera serie: los viajes. O mejor, las migraciones, como desplazamientos puntuales (con una finalidad, una razón o un motivo) aunque lleguen Cleo y Qüity a un destino imprevisible. No se trata de itinerarios afirmados en la supuesta prosperidad que la globalización garantizaría; aquí el traslado implica un intervalo, la suspensión, donde caben todos los cuestionamientos, todos los replanteos de un proceso histórico afirmado en una especie de antiteleología del progreso, una antidialéctica de la evolución. No son las naciones interconectadas entre sí que albergan los derechos de la ciudadanía; son grupos, individuos, multitudes que derivan hacia destinos inciertos sin promesa ni devolución. Cabezón Cámara marca un punto de inflexión entre lo local y lo global, lo barrial y lo urbano, la comunidad y la nación, la naturaleza y la cultura (Ranciere, 2007). Y si se piensan como dicotomías, el conflicto social y cultural que plantean los textos permite suponer la disolución en ciernes, los términos desagregados de grupos y sectores que van a disolverse en la amnesia gradual de su pasado. La zona baldía, entonces, será el destino de las migrantes venidas a millonarias. La memoria será el repositorio autobiográfico, o mejor, biografías de los muertos encarnados en la conciencia y la voz de la narradora devastada, convertida en amasijo de recuerdos a la deriva, rotos, despedazados.

Cuarta serie: la maternidad. La biológica (Cleopatrita), y la elegida por adopción: Kevin. Aquí la narradora queda casi en segundo plano porque es el niño quien la adopta, la realiza y ella se vuelve a crear en ese lugar de contención. Al decir de Sloterdijk (2001), releyendo a Nietzsche, en la soledad extrema y elegida, en el despojo y el desamparo de la incertidumbre que en el caso de Qüity es siempre a un paso de la muerte, la libertad plena le otorga el crédito: el reconocimiento de un instante, el que define el nuevo lazo plenamente amoroso. Es la maternidad lo que marca el ritmo entre la libertad dentro del caos, el goce del riesgo; la maternidad inaugural de una nueva "ontología", extraviada deliberadamente entre la pulsión de la naturaleza y el mandato de la cultura. El encuentro, el hallazgo entre Kevin y Qüity es la síncopa que privilegia el afecto (sensible y corporal) a la ley familiar. Se diría, ley consuetudinaria del afecto entreverado en el lenguaje de abrazos, juguetes y meriendas, antepuesto a la maternidad refrendada como acta civil y documental. El lazo indeleble entre Kevin y Qüity, podría decirse también, sustituye enteramente a la ley, eje que funda "la célula básica de la sociedad". Afectividad biomolecular, de vida extendida en la in-tensidad de los límites y del hallazgo auspiciado en el puro azar. Maternidad y familia por elección y por encuentro, fortuito, sin causa, re-conocimiento mutuo en la primera mirada que sin embargo le devuelve algo perdido, repitiendo la instancia de un olvido en la afirmación que prescinde de toda duda: lo que se repite y vuelve, sin parecerse a nada, es la respuesta a una necesidad innominada. Como si Kevin 
fuese la "iluminación profana" de una señal, el llamado y el cascabel del cuerpo y de la piel sensible al re-conocimiento mutuo. Y esta será el cerco absoluto, ineluctable.

El asesinato de Kevin durante el operativo político policial expulsa la posibilidad ilimitada del humor. Las connivencias de la ilegalidad entre las instituciones estatales son la contracara de la vida organizada en los códigos propios de una comunidad. Pero el afecto, llevado al extremo del amor incondicional e incondicionado, sin techo ni suelo, por ello desprotegido en la neutralidad (nec-uter, sin útero, en el sentido de Blanchot); un espacio en blanco, vacío de manto estelar. Qüity es la trapera de reliquias arrasadas en un tiempo sin pasado ni futuro, en un presente continuo cuyo atributo más cruel es ir borrando lentamente la imagen de los seres queridos: lo visual, pero también su olor y su sonido. Ahí se cifra la certera sensación de pérdida y de una distancia sin sentido, el sentimiento del naufragio. "Mis pensamientos eran cosas podridas, palos, botellas, camalotes, forros usados, pedazos de muelle, muñecas sin cabeza, la reflexión del collage de desperdicios que la marea deja amontonados cuando baja después de subir mucho" (Cabezón Cámara, 2009: 9).

Cabezón Cámara, evocando el abrazo soñado entre Odiseo y su madre muerta, roza el decir de lo imposible: decir el dolor máximo para el que no se creó la palabra. Ahí, parafraseando a Didi-Huberman (2011), se produce una suerte de heterocronía, apelando a la condición mortal de lo humano. Antes de narrar, saca fuerza del cuerpo, del latido forzado y de la respiración. Y libera el estertor ante un sueño temido porque el despertar malsano le revela la realidad. Es la desesperación por un duelo imposible. Historia de la memoria sensible, el decir de la imagen tiempo, detenido para siempre en el niño acribillado, su mano tendida hacia su juguete roto. Si algo restituye la pérdida, es la sola posibilidad de fundirse en la muerte de Kevin, consustanciada Qüity en la insistencia de la última imagen: "había visto en las filmaciones ese cuerpito desordenado por la muerte, la sangre fluyendo de su cabeza hasta que se secó Kevin y después la sangre también se secó" (Cabezón Cámara, 2009: 12). Tan ilimitado es el dolor que hasta se seca el llanto para que no quede más tiempo ni fuerza que retorcerse hacia lo más bajo que se pueda, en la posición prenatal sin que auspicie devolución a las plegarias. Pero, acto seguido, Qüity lo encuentra en la cocina en la paradoja doliente de la espera, el deseo de verlo, tocarlo, oírlo, contra la verdad ineluctable que negándole el deseo lo convierte en absurdo. La obstinación que asimismo le niega la pacificación del duelo le da resonancia específica al nombre de Kevin y lo vuelve cuerpo al hijo "adoptivo", el cuerpo y la materialidad que el azar hizo que no naciera de su propio vientre. Los detalles lo vuelven figuración del padecer más extremo, de la pena más honda, herida abierta y punción que asfixia, y la pequeña manito que atravesaba la taza, pierde "toda la solidez de este mundo" para desvanecerse en un aire nimbado de fantasmas. No puede haber duelo donde no hay cicatriz, para Qüity muerta también en el vacio del pasado, y zombi porque transita el mundo muerta en la muerte de su hijo. El lenguaje, la sintaxis, antepone el adjetivo en cuanto condición e imagen de la subjetividad. "[N]áufraga me sentía", "Con Kevin soñaba", más allá del ritmo de letanía y lágrima que no cesa, porque el tono y el pretérito del fraseo connota un continuo, el sujeto se pospone a presencia / ausencia incidental, al niño ángel que es acontecimiento y contingencia. Y como tal, la narradora lo antepone, lo sitúa en el principio de la escala, en todas las dichas y todas las tristezas. "Cuando lo que se espera aún contra toda esperanza llega" (Cabezón Cámara, 2009: 12); "pura materia enloquecida de azar, eso, pensaba, es la vida" (Cabezón Cámara, 2009: 9), sentencia Qüity anunciando explícita que se puso aforística. Pero si como acto de enunciación, las frases interpelan la conmoción emotiva de sus congéneres, como gesto evocan la reflexión, es decir, la flexión o el doblez sobre su propio cuerpo, la introspección que duplica la posición fetal en la que se halla mientras navega por las islas del Paraná. 
La muerte de Kevin la expone al desgarro más absoluto, lacerada narrando, por deseo, la sensación corporal de cercanía. Fotosíntesis, tierra, aire, raíces y tormenta, ensalada o "lombriz para alimentar bagres". Kevin no está "en el cielo, feliz", como repite, convencida, Cleo. Por eso, el sueño le concede un lugar donde, desde siempre, madre e hijo se esperan y se aferran en una conversación de palabras y silencios. Qüity, flotante sin soporte porque el momento de la merienda y la puesta al día de las novedades se corta abruptamente para volver a morirse en la nueva y repetida separación de cada día. Qüity aferrada a la imagen filial para despertar a la pesadilla de la realidad que solo le devuelve la ausencia. Narrar la experiencia sensitiva del latido en la falda al momento de abrazar. 
Cabezón Cámara, G. (2009). La Virgen Cabeza. Buenos Aires, Eterna Cadencia.

"---------- (2014). Romance de la Negra Rubia. Buenos Aires, Eterna Cadencia.

»Cabezón Cámara, G. y Echeverría, I. (2012). Beya. Le viste la cara a Dios. Buenos Aires, Eterna Cadencia.

\section{Bibliografía de consulta}

»Butler, J. (2009). El género en disputa. Barcelona, Paidós.

»Didi-Huberman, G. (2011). Ante el tiempo. Historia del arte y anacronismo de las imágenes. Buenos Aires, Adriana Hidalgo.

"Domínguez, N. (2014). Conversaciones y reenvíos con Gabriela Cabezón Cámara. En Cuadernos LIRICO, 10. En línea: https://journals.openedition.org/ lirico/1653 (consulta: 29-08-2018).

"Esposito, R. (2007). Communitas. Origen y destino de la comunidad. Buenos Aires-Madrid, Amorrortu.

» Fernández, N. (2015). La lengua como puñal: entrevista a Gabriela Cabezón Cámara. En Diario Telam, Suplemento Cultural, noviembre. Buenos Aires. Versión ampliada y actualizada en Hispamérica, no. 138, 2017, Maryland, USA.

»Groys, B Antinomies of Art and Culture Modernity. Postmodernity, Contemporaneity, Duke University Press, 2008.

» ancière, J. (2007). En los bordes de lo político. Buenos Aires, La Cebra.

» Sloterdijk, P. (2001). Extrañamiento del mundo. Valencia, Pre-textos. 
